\title{
El estatuto de la subjetividad en la teoría polifónica de la enunciación
}

\author{
ADRIÁN BERTORELLO \\ UNIVERSIDAD DE BUENOS AIRES
}

RESUMEN: El trabajo se propone discutir el rol que cumple la subjetividad en la teoría polifónica de la enunciación de Ducrot. La tesis que desarrolla es la siguiente: existe una contradicción entre el punto de partida que Ducror asume, a saber, el supuesto saussuriano de la inmanencia del análisis lingüístico con su propuesta de una diversidad de roles subjerivos que hablan en los enunciados. Sólo rompiendo con la inmanencia ligüística y adoptando una teoría de la subjetividad histórica muy cercana a la de Bajtín es posible sostener la idea de una enunciación polifónica. Finalmente, el trabajo propone una reorganización de los roles subjetivos polifónicos a partir de las nociones de modalidad y deixis.

Palabras Clave: Polifonia, Sujeto, Modalidad, Deixis.

RESUMO: O trabalho se propõe discutir o papel que cumpre a subjetividade na teoria polifônica da enunciação de Ducrot. A tese que desenvolve é a seguinte: existe uma contradição entre o ponto de partida que Ducrot assume, a saber, o suposto saussuriano da imanência da análise lingüística com sua proposta de uma diversidade de roles subjetivos que falam nos enunciados. Só rompendo com a imanência ligüística e adotando uma teoria da subjetividade histórica muito próxima daquela de Bajtín é possível sustentar a idéia de uma enunciação polifônica. Finalmente, o trabalho propõe uma reorganização dos papéis subjetivos polifônicos a partir das noções de modalidade e deixis.

PalaVRas ChaVE: Polifonia, Sujeito, Modalidade, Deixis.

ABSTRACT: This study aims at discussing the role that subjectivity plays in Ducrot's polyphonic theory of enunciation. The thesis developed is the following: there is a contradiction between the starting point that Ducrot assumes, i.e., Saussure's idea about the immanence of the linguistic analysis and his proposal of a diversity of subjective roles that speak in the enunciation. I claim that only by breaking the linguistic immanence and adopting a theory of historical subjectivity close to Bajtin's it is possible to maintain the idea of a polyphonic enunciation. Finally, the study proposes 
a reorganization of the polyphonic subjective roles from the notions of modality and deixis.

Key Words: polyphony, subject, modality, deixis.

\section{Introducción}

El fin del presente ensayo es determinar el alcance y los límites de la concepción del sujeto implicada en la teoría polifónica de la enunciación de O. Ducrot ${ }^{1}$. La pregunta fundamental que intentaré desarrollar $y$ eventualmente responder es la siguiente: ¿cuál es el estatuto de la subjetividad en una teoría que describe la enunciación como una escenificación de diversos roles subjetivos? Esta pregunta expresa el mismo problema que María Luisa Donaire formula en el texto que sigue:

Si bien el locutor y enunciadores pertenecen ambos a la imagen que ofrece el enunciado de su propia enunciación, las "voces" que deja "oír" un enunciado no tienen todas el mismo estatuto (Donaire, 2000: 75).

La cuestión del estatuto de las voces que el locutor hace oír en el enunciado es sólo una parte del problema general del estatuto de la subjetividad. En efecto, al problema de la subjetividad no sólo pertenecen nociones tales como "locutor", "enunciador", "locutor $\lambda$ ", "voces" y "punto de vista", sino también el concepto de "sujeto hablante". Las relaciones entre todos estos roles subjetivos expresan el problema general del estatuto de subjetividad.

Ahora bien, las preguntas que surgen de esta caracterización del problema son: ¿qué significa preguntar por el estatuto de algo? ¿qué es el estatuto de la subjetividad? Si bien no aparece en los textos de Ducrot tal como lo voy a decir, y, en rigor, la posición que voy a adoptar va en cierto sentido en contra de la letra del texto (Ducrot, 1986: 200), creo que estas preguntas remiten el problema necesariamente a un plano que no es estrictamente lingüístico, sino ontológico. Preguntar por el estatuto de la subjetividad significa plantear una cuestión que opera como presupuesto del pensamiento de Ducrot, pero que se manifiesta en ciertas expresiones que usa sin explicar ("ser del discurso", "ser del mundo"). Esta cuestión es la del ser del sujeto de la enunciación. Plantear el problema del estatuto de la subjetividad significa determinar diversos tipos de sersujeto y diversas regiones ontológicas que no son otra cosa que las jurisdicciones o ámbitos de influencia semántica en donde operan dichos sujetos. La discusión se desarrollará, por lo tanto, en un nivel metateórico.

La exposición seguirá el siguiente recorrido. En primer término voy a presentar brevemente la teoría de la enunciación polifónica de O. Ducrot 
y la interpretación que María Luisa Donaire (2000) hizo de la misma. En la segunda parte del trabajo haré algunas consideraciones críticas a la teoría.

\section{La polifonía y los niveles del lenguaje}

\subsection{LA CONCEPCIÓN POLIFÓNICA DE LA SUBJETIVIDAD}

Para entender correctamente la teoría de Ducrot es necesario, ante todo, ver cuál es la finalidad de su propuesta y cuál es la metáfora fundamental que está en el punto de partida de su pensamiento. Ducrot se propone refutar una teoría dominante en la lingüística moderna. Esta teoría concierne a la subjetividad. Ducrot presenta sus análisis como una crítica al estatus de la subjetividad que prevalece en el estructuralismo, generativismo y comparativismo. Todas estas corrientes postulan la unicidad del sujeto hablante (Ducrot, 1986: 175) o, lo que es lo mismo, la unicidad del sujeto de la enunciación (Ducrot, 1986: 193). Ello significa: a cada enunciado le corresponde uno y sólo un sujeto de la enunciación. Este sujeto es el responsable y el autor del enunciado. Posee tres rasgos específicos (Ducrot, 1986: 193-196): a) despliega la actividad psicofísica que produce los enunciados, b) es el origen de los actos elocutivos, y c) posee las marcas de la primera persona.

La intención no sólo es criticar esta noción de enunciación, sino reemplazarla por una teoría polifónica. Esta nueva teoría tiene sus antecedentes en la interpretación polifónica de la novela de Bajtín y se inspira directamente en los trabajos de Authier y Plénat (Ducrot, 1986: 177). Sin embargo, los nuevos conceptos que Ducrot introduce para explicar los diversos roles que el sujeto puede asumir provienen de una metáfora. Lo que Ducrot llama la "metáfora teatral" (Ducrot, 229-230). El campo semántico de donde surge la polifonía es el teatro. La metáfora supone la siguiente comparación: del mismo modo que el autor teatral pone en escena distintos personajes, cada uno con su propio punto de vista; y del mismo modo que el autor adopta diversas actitudes frente a ellos, es decir, a veces se identifica con uno de sus personajes, otras veces se separa críticamente, así también sucede con el lenguaje: los enunciados producidos por el hablante son el escenario en donde actúan diversos puntos de vista sobre lo dicho. El hablante también toma posición frente a los puntos de vista. Lo decisivo de la metáfora fundante es la diversidad de roles subjetivos: autor versus personajes, hablante versus puntos de vista.

Como complemento de esta metáfora Ducrot recurre a una analogía teórica muy importante desde el punto de vista del estatus de la 
subjetividad. Me refiero a la teoría narrativa de Genette (1989). Cada uno de los conceptos introducidos por Ducrot para dar cuenta de los distintos roles subjetivos tienen un paralelo en las categorías narrativas (Ducrot, 1986: 213). Genette distingue tres categorías del relato: tiempo, modo y voz. Mientras que el tiempo y el modo corresponden al nivel de análisis del enunciado, la voz corresponde al de la enunciación (Genette, 1989: 86-87). La noción de Ducrot de punto de vista es análoga al concepto modal de focalización de Genette, mientras que el locutor es análogo a la voz narrativa. La asimilación del locutor a la voz es lo que le permite a Ducrot distinguir entre el sujeto hablante real y el sujeto que habla en el discurso.

Esta última afirmación posee una relevancia fundamental. La razón de ello está en que distingue dos órdenes autónomos del ser: el ser real y el ser del discurso. A la primera dimensión pertenece el sujeto como un ser biopsicológico y a la segunda como una entidad de la lengua. La expresión "ser del discurso" describe el plano inmanente de la lengua. Ducrot se mantiene dentro de los supuestos establecidos por Saussure. Ello se puede apreciar claramente cuando finaliza su análisis de la ironía. Pareciera que la semántica de la ironía sólo puede ser comprendida en el plano del habla (Ducrot, 1986: 218). Ducrot se opone a esta interpretación y para evitar la confusión, por un lado, remite a su distinción entre sentido y significación y, por otro, se aboca a la semántica de la negación. A propósito de ella dice: "Nadie discutirá que la negación es un hecho de la lengua" (Ducrot, 1986: 219).

Así entonces, en el punto de partida se hallan cuatro elementos que definen el perfil teórico de la concepción polifónica de la enunciación: a) la discusión se lleva al plano de la teoría del sujeto, b) la metáfora que guía la creación de conceptos es uno de los géneros literarios tradicionales, el teatro, específicamente los ejemplos están tomados del teatro clásico de Molière, c) el análogo teórico es la teoría narrativa de Genette, teoría que construye sus conceptos a partir un texto literario complejo, En busca del tiempo perdido, d) el supuesto ontológico no discutido es la distinción entre un sujeto real -biopsicológico- y un sujeto de la lengua. Este supuesto proviene de la decisión de Ducrot de mantenerse dentro de los límites establecidos por la tradición de Saussure.

Una vez establecidos estos principios generales, voy a detenerme en dos cosas: en primer lugar, haré una breve exposición de los conceptos fundamentales que describen el marco teórico desde donde Ducrot aborda la polifonía. En segundo lugar, voy a referirme a los términos que él introduce para explicar la condición polifónica de la subjetividad.

Ducrot denomina "semántica pragmática" o "pragmática lingüística" al marco teórico al que pertenecen sus investigaciones sobre la polifonía. 
La tesis central de esta disciplina es un cambio del punto de vista en lo tocante al acto de enunciación. En efecto, no se trata de ver qué hace un sujeto al hablar, sino de lo que el habla hace. La enunciación es una acción que no se le debe imputar a un sujeto que obra aqui y ahora, sino al enunciado mismo, al habla:

Ass pues, el objeto de la pragmática semántica (o lingüística) es dar cuenta de aquello que, según el enunciado, el habla hace (Ducrot, 1986: 178).

De esta caracterización del objeto de la pragmática se sigue que los conceptos clave de su teoría son dos: enunciado y enunciación. El enunciado se diferencia de la frase, que es una construcción teórica del lingüista, por los siguientes rasgos: a) es un acontecimiento y, como tal, supone las coordenadas espacio-temporales, es decir, ocurre aquí y ahora, b) el acontecimiento se pone en marcha por las elecciones que un sujeto hablante hace, y c) esas elecciones son relativamente autónomas. La cohesión y la independencia del enunciado dan cuenta de esta autonomía (Ducrot, 1986: 179).

Desde el punto de vista semántico a la frase le corresponde la significación, mientras que al enunciado el sentido. La diferencia entre significación y sentido no sólo es metodológica, sino también es esencial. Por decirlo así: la significación hace abstracción del acto de enunciación que da origen a los enunciados implicados en ella. Por ello, dice Ducrot que es un conjunto de instrucciones. Cuando un hablante lee la frase, actualiza los enunciados implicados en ella, es decir, interpreta las instrucciones y atribuye un sentido a los enunciados. De aquí se sigue que el sentido es la descripción de la enunciación (Ducrot, 1986: 187). El sentido de un enunciado depende del acto de enunciación. Sin esta referencia a ella, los enunciados carecen de sentido. De ahí que se pueda decir esquemáticamente que la diferencia entre sentido y significación sea la referencia o la ausencia al acto de la enunciación ${ }^{2}$.

Como se puede ver, el concepto de enunciación tiene un rol fundamental en la semántica del enunciado. El análisis de la enunciación tiene dos momentos. En el primero Ducrot hace un análisis como lingüista, en el segundo como semántico. Es en este segundo momento cuando introduce la teoría polifónica de la subjetividad. La diferencia que hay entre las dos perspectivas es la siguiente: para la lingǘstica el acto de la enunciación no puede ser imputado a nadie, para el semántico el acto de la enunciación tiene que ser imputado a diversos sujetos.

En el análisis lingüístico le asigna dos rasgos: a) la enunciación no tiene que ser interpretada como los procesos biopsicológicos realizados por un determinado sujeto. La enunciación es, por decirlo así, anónima, en el sentido de que, no remite ni a la noción de acto, sujeto, acto de 
habla o autor. Sólo se limita a constatar la aparición histórica del enunciado. La enunciación da cuenta del acontecimiento anónimo por el que el enunciado cobra existencia histórica (Ducrot, 1986: 183). Funciona como los verbos de acontecimiento que describen una acción sin imputarla a un sujeto que la realiza, b) recurre nuevamente al ámbito literario para ilustrar que el enunciado es una parte de la enunciación. Del mismo modo que en la tapa de un libro lleva el nombre del autor, así también sucede con el enunciado y su enunciación (Ducrot, 1986: 193). Todo enunciado lleva las marcas de su enunciación.

$\mathrm{El}$ análisis semántico de la enunciación es el que da lugar a la teoría polifónica de la subjetividad. La introducción de diversos roles subjetivos sólo es posible cuando se pasa de una consideración lingüística a una semántica (Ducrot, 1986: 197-198).

Los enunciadores, el locutor, el locutor $\lambda$ y el sujeto hablante son los diversos roles subjetivos que describen la polifonía de la enunciación. Ducrot ilustra estos conceptos con diversas expresiones polifónicas, a saber, el estilo directo, el eco, la ironía, la negación, los actos de habla y la argumentación. Dejo de lado los análisis de los ejemplos y presento a continuación el sentido de los diferentes roles del sujeto. El punto de partida es una categoría ontológica: la oposición entre ser empírico versus ser del discurso (Ducrot, 1986:204):

a) Ser empírico: a este dominio ontológico corresponde la noción de sujeto hablante. Es aquel que confiere existencia real mediante una serie de procesos biopsíquicos a un número $\mathrm{x}$ de enunciados. Es el equivalente al autor de una obra en la teoría de Genette.

b) Ser del discurso: a este dominio pertenecen los restantes roles subjetivos. b.1) Locutor (L): es la fuente de la enunciación, aquel a quien se le debe imputar la responsabilidad del enunciado. Su equivalente en la teoría de Genette es la voz narrativa.

b.2) Locutor (l): el locutor en tanto ser del mundo. Esta expresión ambigua, en la que pareciera que se da un salto ontológico al ser empírico, tiene el sentido siguiente: ese locutor da cuenta de la objetivación en el plano del discurso. Es el punto de vista objetivo en donde a l se lo considera como tercera persona, por ello puede ser objeto de reflexión y determinar sus cualidades como si fuera un ser del mundo. Por ello creo que corresponde a una determinado punto de vista; parafraseando a Nangel (1996: 81-99), es aquella perspectiva que mira desde ningún lugar, mirada que es un artificio del mismo discurso y que considera al locutor como si fuera un ser del mundo. El locutor 1 da cuenta de la propiedad del discurso de elidir el acto de enunciación atribuido al locutor (L). La elipsis del rol subjetivo del locutor no arroja como resultado la desaparición de todo tipo de subjetividad, sino que da lugar 
a otro tipo, a saber, aquella que puede ser vista desde afuera, como si fuera una tercera persona. Esta perspectiva es la que constituye a l.

b.3) Los enunciadores: son los puntos de vista y las actitudes que el locutor pone en escena en el enunciado, a veces se identifica con alguna y otras veces pone distancia. Corresponde a la categoría modal que Genette denomina focalizaciones.

\subsection{LOS NIVELES DEL LENGUAJE}

María Luisa Donaire (2004) reelaboró la teoría polifónica de Ducrot. Su intención fue precisar el estatuto lingüístico de los distintos roles subjetivos que el enunciador puede asumir. Su tesis fundamental se puede resumir así: la polifonía es una relación binaria que opera en distintos niveles del lenguaje. La unidad polifónica fundamental que recorre cada uno de los niveles es el punto de vista.

Existen cuatro niveles de análisis polifónico. Cada uno de ellos se ordena según el eje de la profundidad/superficialidad. A pesar de este ordenamiento no existe entre ellos una relación jerárquica. Lo que define a cada nivel es el estatuto de sus unidades (Donaire, 2004:123).

El nivel más profundo es el lingüístico. Aquí el analista se mueve en el plano de la lengua; se enfrenta con la polifonía inherente a las unidades léxicas. A este nivel pertenece la noción de punto de vista. Es en este contexto en donde Donaire define la noción de punto de vista como el discurso determinante de una unidad léxica ${ }^{3}$. En la medida en que existen distintos discursos $(\mathrm{X}, \mathrm{L} \circ \mathrm{Z})$ que pueden elegirse para determinar la relación semántica de una unidad léxica, se dice que los discursos están orientados argumentativamente. Es por ello que el punto de vista supone la elección de una orientación argumentativa y la exclusión de otras. De esta manera Donaire interpreta la noción de Ducrot de significación:

El significado de toda unidad léxica, configurado en forma de instrucciones de uso, se define necesariamente como una orientación argumentativa dererminada, una forma $\mathrm{X}$ de enunciar $(\mathrm{X}, \mathrm{Y}, \mathrm{Z}) \mathrm{A}$, una forma de argumentación $\mathrm{XA}$, un punto de vista (Donaire, 2004: 126).

La relación polifónica binaria del nivel de la lengua está dada por las operaciones de selección y exclusión argumentativa. Estas dos opciones dan lugar a dos puntos de vistas que Donaire llama "argumentación favorable" "y "argumentación desfavorable" 5 . En el caso de las unidades léxicas que carecen de cualquiera de estas dos marcas argumentativas Donaire sostiene que, por defecto, dan cuenta del punto de vista favorable.

El segundo nivel de análisis polifónico es el frástico. Aquí el analista se mueve también en el nivel de la lengua, pero se enfrenta ya no con las unidades léxicas con significación independiente como adorable/detesta- 
ble, sino con aquellas que cumplen la función de relacionar unidades léxicas entre sí ("pero", "no obstante", "por lo tanto" etc.), es decir, los conectores, operadores y estructuras sintácticas que cumplen ese rol. Por ello, la unidad que define este nivel es la frase. El significado de las frases depende de una nueva unidad polifónica: la relación entre puntos de vista. Este nuevo nivel de análisis polifónico se estructura como una relación argumentativa binaria favorable o desfavorable (Donaire, 2004: 127). Asimismo, las frases que carecen de marcas argumentativas tienen que ser interpretadas, por defecto, como una orientación favorable.

El tercer nivel es el enunciativo. Aquí la unidad de análisis es el enunciado. El sentido del enunciado depende de los puntos de vista que el locutor, en tanto responsable total del enunciado, convoca. La representación de estos puntos de vista adopta la forma de un debate entre distintos enunciadores. La polifonía en este nivel supone, entonces, la distinción entre el locutor en tanto que tal (L) y los enunciadores (E) responsables de los puntos de vista convocados por L (Donaire, 2004: 124). Como se puede apreciar claramente, la relación polifónica asume también un carácter binario. La distinción entre uno y otro -de carácter formal- se da por la responsabilidad enunciativa: el locutor es el responsable de la enunciación y del enunciado, mientras que los enunciadores son los responsables de los puntos de vista dados en el enunciado (Donaire, 2004: 125).

Pareciera que el ámbito de jurisdicción entre uno y otro es la distinción entre el nivel de la enunciación en donde el locutor es el responsable del enunciado, y el nivel del enunciado, en donde los enunciadores son los responsables de los puntos de vista. Ellos (E) son los que pueden tener relaciones argumentativas favorables o desfavorables respecto de las instrucciones significativas dadas en el léxico y en la frase. Es decir, ellos son los responsables de las operaciones de selección y exclusión. Ahora bien, esta interpretación parece quedar anulada cuando, a continuación, Donaire dice:

Todos los puntos de vista que se manifiestan en el enunciado surgen de una misma selección del locutor, así como las relaciones que se establecen entre ellos, lo que da unidad al enunciado y define una única orientación, responsabilidad que se atribuye al locutor en el enunciado (Donaire, 2004: 129).

Con ello se quiere oponer a la imagen de un debate en donde el locutor pone en escena distintos enunciadores con sus puntos de vista propios y luego el locutor toma posición respecto de ellos. Según la cita, la responsabilidad de todos los puntos de vista se atribuyen al locutor a fin de garantizar la unidad de sentido del enunciado. Pero paradójicamente al concluir su análisis del nivel enunciativo dice: 
La operación de selección / exclusión del punto de vista que señala la orientación del enunciado define al locutor, así como la operación de selección /exclusión de cada uno de los puntos de vista convocados define a los enunciadores (Donaire, 2004: 130).

Finalmente, el cuarto nivel es el discursivo. La polifonía en este nivel se produce por la identificación de los puntos de vista y los enunciadores con personajes del discurso. Los personajes son el locutor $\lambda$ (locutor en tanto ser del mundo), el alocutor, cualquier persona o grupo social. Donaire los describe como "personajes de los que habla el enunciado, son representaciones de la enunciación” (Donaire, 2004: 130). Más precisamente: "...lo que en gramática se acostumbra a denominar como "tercera persona" y que podríamos englobar en una teoría polifónica bajo la etiqueta alocutario" (Donaire, 2004: 130). También en este nivel la relación es binaria, se da como un debate entre argumentaciones favorables/desfavorables que identifican las posiciones de los diversos personajes del discurso.

\section{Consideraciones criticas}

En esta parte del trabajo voy a exponer las dificultades teóricas que encierra la teoría polifónica de la subjetividad tanto en su versión original como en la interpretación de María Luisa Donaire. Voy a organizar la exposición en dos momentos, uno crítico y otro positivo.

En el primero mostraré que el estatuto de los roles subjetivos es confuso no porque, como dice Donaire, el texto de Ducrot sea "excesivamente concentrado" (Donaire 2004: 131), sino porque el punto de partida de sus reflexiones le impide una correcta comprensión de los fenómenos que quiere explicar. Dicho de otra manera: Ducrot parte de una tradición de pensamiento inadecuada para dar cuenta de la diversidad de roles que el sujeto puede asumir. Esta es la razón de las ambigüedades y contradicciones que la teoría encierra.

En segundo lugar, propondré una explicación alternativa del estatuto de la subjetividad polifónica. Creo que los diversos roles que Ducrot propone se distinguen realmente y adquieren su verdadero estatus cuando se los vincula con los conceptos de la deixis y la modalidad.

\subsection{CRÍtICA A LOS SUPUESTOS DE LA TEORIA POLIFÓNICA}

Las dificultades que tienen Ducrot y Donaire en la distinción y atribución de funciones semánticas a los diversos roles subjetivos se deben a los supuestos teóricos que admiten sin discutir. Creo que el problema que Ducrot advierte en el comienzo de sus reflexiones, a saber, la imposibilidad de la lingüística moderna de hacerse cargo de las múltiples subjetivi- 
dades del discurso, es realmente cierto. Pero desde el punto de vista teórico, la propuesta de Ducrot no se aparta en nada de lo que critica. En efecto, comparte con la lingüística moderna el prejuicio de que el punto de partida y de llegada de sus análisis es el plano de la inmanencia de la lengua.

Las preguntas que surgen son las siguientes: ¿en el sistema de la lengua hay lugar para el sujeto? en el caso de que lo hubiera ¿qué tipo de subjetividad es el que está implicado en ella? ¿un sujeto único? ¿una multiplicidad de sujetos? ¿un sujeto histórico? ¿un sujeto trascendental? ¿un sujeto empírico? El sistema de la lengua es anónimo, no deja lugar para la subjetividad. O para ser más preciso, ya que es imposible eliminar por completo la subjetividad, el tipo de sujeto implicado en el plano de la inmanencia es lo que Voloshinov llama el enunciado monológico (Voloshinov, 1992: 105 y 119), la mirada de la tercera persona que, desde ningún lugar, observa. El objeto de investigación del lingüista es una construcción teórica y, como tal, sólo puede ser constituida por un sujeto epistemológico. Este sujeto habla bajo la forma del monólogo y mira desinteresadamente. En ningún caso puede dar lugar a una pluralidad de voces, actitudes y roles subjetivos; es monolítico. En esto radica la contradicción del punto de partida: justificar la polifonía a partir de una concepción del lenguaje que no deja lugar a la diversidad de intereses argumentativos. Es contradictorio porque una subjetividad polifónica es irreconciliable con un sujeto epistemológico.

La contradicción entre el punto de partida y la propuesta teórica se deja advertir fácilmente en la imprecisión y ambigüedad con la que Ducrot define sus conceptos fundamentales:

a) La distinción entre una semántica del enunciado y otra de la frase sólo tiene sentido cuando se opone el sistema de la lengua al discurso entendido como la apropiación de la lengua que hace un sujeto en una determinada situación comunicativa práctica. Ducrot reconoce esta distinción cuando dice que el enunciado se caracteriza por las elecciones históricas (aquí y ahora) que hace el sujeto hablante. Ahora bien, describir así el enunciado significa necesariamente salirse de la inmanencia de la lengua. La lengua como sistema no elige absolutamente nada, sólo ofrece en el plano de la posibilidad opciones, reglas. Pero la elección efectiva sólo puede ser imputada a un ser que tiene estados intencionales y que obra conforme a ellos aquí y ahora. En otros términos: las elecciones lingüísticas constitutivas de los enunciados son actos de libertad. La lengua no deja espacio para la libertad, sino que se mueve en el plano de la necesidad. La necesidad no puede constituir diversidad de sujetos que tienen intereses argumentativos antagónicos. La necesidad sólo da lugar a un único sujeto que tiene la responsabilidad absoluta y única del discurso. 
b) La enunciación es el otro concepto sumamente oscuro que resulta de la contradicción entre supuesto y propósito. Ducrot hace dos descripciones de la enunciación: en tanto lingüista es un acontecimiento anónimo, en tanto semántico es un acontecimiento que se le debe imputar a varios sujetos. Esta distinción sólo tiene sentido si y solo si se opone el plano de la inmanencia con el plano de la realidad histórica en donde un sujeto conforme a sus intereses argumentativos manipula el lenguaje y asume distintos roles. La estrategia es un acto de la enunciación histórica. Asimismo, la distinción de puntos de vista de análisis es paradójica porque ¿tiene sentido hablar de un acto de enunciación en la lengua? ¿qué aporta a la significación la enunciación? ¿una enunciación que se limita a constatar la aparición del enunciado no se transforma en un concepto residual? El concepto de enunciación sólo tiene sentido en el discurso, concepto que Ducrot y Donaire nunca definen. Pero a su vez, cuando Ducrot está tratando la polifonía, es decir, cuando hace un análisis semántico de la enunciación, vuelve a sostener que su concepción de la misma no alude a ningún autor individual, es decir, que no puede ser imputada a ninguna subjetividad (Ducrot, 1986: 1999-200). Este es el caso de los enunciados históricos que no llevan la marca de la enunciación. Habría una enunciación impersonal, pero en vez de problematizar teóricamente esa dificultad, Ducrot se limita a decir que hay ciertos enunciados que no tienen marcas de la enunciación. Este ir y venir de una postura a otra arroja como resultado que la distinción entre una interpretación lingüística de la enunciación y otra semántica sea muy poco clara.

c) La distinción entre locutor como responsable del enunciado y los enunciadores como los puntos de vista relativos a los enunciadores es problemática. Esta distinción proviene de Genette, para quien la voz y el modo (los puntos de vista) pertenecen a planos distintos de análisis. La voz da cuenta de la enunciación y el modo (al igual que el tiempo) corresponde al enunciado. Creo que es imposible concebir el concepto semántico de modalidad como algo ajeno a la enunciación, ya que los puntos de vista (sean los propios de la voz narrativa u otros que esa voz pone en juego) siempre dan cuenta de las posiciones y actitudes del sujeto frente a lo dicho ${ }^{6}$. Una vez aceptado que el locutor y los puntos de vista de los enunciadores pertenecen al plano de la enunciación, el problema radica en determinar si existe una diferencia conceptual entre ellos, es decir, si la voz da cuenta del punto de vista del locutor frente a los puntos de vista de otros enunciadores que aquel pone en escena en el enunciado. En este caso la voz queda subsumida bajo la noción de punto de vista. $O$ si la voz cumple una función semántica distinta de los puntos de vista. Donaire rechaza la primera posibilidad porque no se distinguirían las dos 
instancias (locutor y punto de vista) (Donaire, 2004: 129). Ella propone la segunda opción:

En Ducrot (1984) queda claro que la responsabilidad de los puntos de vista corresponde a los enunciadores, y el punto de vista que se le puede atribuir al locutor es en todo caso el punto de vista seleccionado para determinar la orientación del enunciado, o lo que es lo mismo, la responsabilidad del enunciado (Donaire, 2004: 129-130).

La distinción estaría en la imputación de la responsabilidad. Creo que la solución es ambigua y confusa. Si el locutor es sólo responsable de las selecciones del enunciado y carece de cualquier tipo de punto de vista frente a los enunciadores, ¿de qué sirve el locutor? ¿cuál es su función semántica? Sería simplemente el doble discursivo del sujeto hablante, aquel que produce el enunciado, incluso su orientación argumentativa, pero que no toma posición frente a los puntos de vista que convocó. Ahora bien, cómo puede ser el locutor responsable de la orientación argumentativa y no tomar posición frente a ella? ¿cómo puede seleccionar sin tener un punto de vista sobre lo seleccionado?

A esta distinción problemática se suma otra: la diferencia entre el locutor $\lambda$, los enunciadores y el locutor (L). Es prácticamente imposible no ver en $\lambda$ otro punto de vista, aquel que mira desde ninguna parte. Si el locutor $\lambda$ es la tercera persona, necesariamente es otro enunciador, es decir, es la modalidad objetiva.

Finalmente, hablar de responsabilidad en el plano de la enunciación significa salirse del sistema de la lengua. Si los distintos roles subjetivos se definen por su responsabilidad enunciativa, entonces nos remitimos a las prácticas de un sujeto histórico que obra de acuerdo a diversos intereses. El sistema de la lengua no da cabida a la idea de responsabilidad.

d) La elección de la metáfora teatral, la analogía con la narratología de Genette (1989) y la dominante de ejemplos literarios están en función del supuesto elegido como punto de partida. Los textos literarios clásicos tienen un altísimo grado de independencia del contexto enunciativo histórico que le dio origen. Por ello, pueden ser abordados fácilmente desde la perspectiva de la inmanencia. Su autonomía semántica (en el sentido de que llevan en sí mismo sus propias condiciones de producción de sentido) están en el extremo opuesto del material lingüístico con que Ducrot y Donaire trabajan: la argumentación. Para decirlo en términos de Bühler: los textos literarios pertenecen al entorno sinsemántico, mientras que la argumentación al entorno empráctico (Bühler, 1999: 154-168). Por ello la siguiente decisión de Ducrot se vuelve en contra de él: "Pues bien, demostraré que esta clasificación, establecida a propósito del lenguaje teatral, tiene un análogo en el lenguaje cotidiano" (Ducrot, 
1986: 230). El lenguaje cotidiano es la antítesis de la inmanencia de la literatura.

e) Ducrot no puede escapar a la dicotomía ontológica que está en la base de sus supuestos teóricos. Los dos modos de ser-sujeto que admite son el ser del discurso (que de acuerdo a las críticas recién formuladas tendría que denominarse más propiamente como el ser inmanente de la lengua) y el ser empírico. El ser de la lengua sería el que da lugar a la teoría polifónica de la subjetividad y el ser empírico es el que habilita al sujeto extralingüístico. La pregunta que surge es esta: ¿cómo concibe Ducrot a este sujeto? El sujeto empírico es el conjunto de procesos biológicos y psicológicos que da existencia a los diversos enunciados. Ciertamente que esta descripción de la subjetividad extralingüística es irrelevante para una explicación lingüística. El sentido de los enunciados no depende de los procesos reales-físicos de su producción. Ahora bien, entre el ser inmanente de la lengua y el ser empírico así descrito existe un tercero: el ser histórico. La historicidad es la cualificación ontológica de la subjetividad humana. El obrar histórico es el que fundamenta el plano del discurso. Este concepto remite siempre a las prácticas históricas del hombre. Por ello, la expresión "ser del discurso" sólo tiene sentido cuando se la restituye a su verdadera dimensión ontológica, la historia. Una teoría polifónica de la subjetividad en el discurso requiere una concepción histórica de la subjetividad.

f) La distinción de niveles de profundidad de la lengua no supera la contradicción entre los supuestos y la finalidad teórica. Con sólo examinar el nivel lingüístico se puede apreciar esta contradicción. En efecto, el léxico como tal, es decir, como perteneciente al sistema, carece de cualquier orientación argumentativa. Las unidades léxicas "adorable/ detestable" sólo pueden tener una orientación favorable/desfavorable para mi. Sin esta referencia a la subjetividad histórica que en un contexto determinado se apropia del sistema, carece de cualquier tipo de orientación axiológica. En el plano de la inmanencia las unidades léxicas sólo tienen valor diferencial, son neutras desde un punto de vista valorativo tal como indican los términos favorable/desfavorable. La dicotomía fundamental de la orientación argumentativa de las unidades léxicas da cuenta de la permanente trasgresión del principio de inmanencia de la lengua. Esta trasgresión se puede constatar también en la distinción de los cuatro niveles. En efecto, el nivel enunciativo y el discursivo se distinguen del léxico y del frástico si se opone la lengua al discurso. A su vez, el nivel discursivo entendido como la identificación de los personajes correspondientes al locutor y los enunciadores es una clara violación de la inmanencia. 


\section{2. El ESTATUTO DE LA SUBJETIVIDAD}

Retomo la pregunta que formulé al principio del trabajo: ¿̨uál es el estatuto de la subjetividad en una teoría que describe la enunciación como una escenificación de diversos roles subjetivos? La primera respuesta a este interrogante es negativa: el ser de un sujeto que puede asumir diversas funciones semánticas no tiene el sentido del ser-inmanente de la lengua. Como se sigue de las críticas formuladas en el punto anterior, la inmanencia sólo puede fundamentar una subjetividad monológica. La segunda respuesta es positiva: sólo en el plano de la historicidad, es decir, del obrar intencional del hombre, es posible fundamentar la polifonía. En la diversidad de la praxis el sujeto representa distintos personajes. Querría glosar esta segunda respuesta en tres puntos:

a) Esta alternativa representa una vuelta a la posición original de Bajtín (1997), para quién el acontecimiento del ser, el acto ético responsable sólo puede ser imputado a un sujeto histórico. Esta manera de comprender la subjetividad no es ajena al lenguaje (Bajtín, 1997: 3839). El concepto de enunciado en Bajtín expresa justamente la referencia del lenguaje a la praxis histórica. La polifonía del enunciado, su bivocalismo, da cuenta de la multiplicidad de roles que el sujeto histórico asume en una situacịón de diálogo ${ }^{7}$.

b) Creo que la metáfora teatral sirve para ilustrar la diversidad de roles de la subjetividad histórica. Pero en una versión mucho más débil que la que propone Ducrot. El modelo que Ducrot tiene permanentemente en cuenta son las obras de Molière. Como obras literarias son totalidades autónomas desde el punto de vista semántico. Este aspecto tiene como consecuencia que sea prácticamente incomparable con el uso cotidiano de la lengua. No obstante, creo que el enunciado es una puesta en escena, una representación dramática, pero en el sentido que Bühler (1999) le asigna a este término. Bühler usa el término "Darstellung" (representación) para explicar la función simbólica del lenguaje. Su sentido es doble: por un lado alude a la facultad del campo simbólico de copiar y reproducir el mundo. Esta primera significación da cuenta del aspecto realista de la teoría en donde el lenguaje reproduce con fidelidad el mundo (Treue der Wiedergaben, Bühler, 1999: 191).

Pero la copia no es una reproducción de las cosas tal como son con independencia del sujeto humano. $\mathrm{Y}$ este es el segundo sentido de la representación lingüística. El lenguaje no es un espejo de la realidad, por ello, no puede ser equiparado con la pintura, la fotografía o el cine (Bühler, 1999: 191). El lenguaje reproduce el mundo bajo el esquema de la acción humana, representa el mundo como un drama. De ahí que use el verbo "darstellen" y no "vorstellen" para referirse a la función simbólica del lenguaje. La representación lingüística del mundo también posee a su modo una orientación subjetiva en la que se distinguen diversos roles. 
c) La distinción entre los roles del locutor, los enunciadores (puntos de vista) y el locutor $\lambda$ pueden ser reorganizados de acuerdo a un doble principio: la deixis y la modalidad. Estos dos conceptos describen la estructura de la enunciación entendida como un acto imputable a un sujeto histórico. De acuerdo a la doble orientación de este acto puede asumir diversos roles.

Según Frawley (1992) la modalidad es una transformación de la estructura de la deixis. Por decirlo así: el sujeto mostrativo es anterior al sujeto modal; su estructura se conserva en la modalidad, pero modificada. Los análisis de Frawley no abarcan todo el fenómeno modal, sino tan sólo se limitan a las modalidades epistémicas y deónticas. Sin embargo, creo que pueden generalizarse a todos los fenómenos modales.

Frawley define la modalidad como la versión epistémica de la deixis. Ello significa: la modalidad no es más que las coordenadas de la deixis descritas por Bühler ${ }^{8}$, pero puestas en relación con el sistema de creencias del hablante (speaker's state of belief). La modalidad es la reescritura epistémica de la deixis (Frawley, 1992: 387-388). El eje de coordenadas del campo mostrativo en el que el yo se constituye como el punto de referencia desde donde se organizan las relaciones espaciales y temporales se mantiene estructuralmente idéntico cuando se pasa al plano de la modalidad. La diferencia radica en que en este nuevo plano entra en juego la constitución epistémica del sujeto mostrativo. El yo de la deixis se comporta ahora como un sujeto que emite juicios y valoraciones, que tiene una actitud epistémica frente a lo dicho en un contexto enunciativo dado ?

La diferencia entre el yo mostrativo y el yo modal es la que -siguiendo nuevamente a Bühler- existe entre el campo mostrativo y el campo simbólico del lenguaje. En efecto, el sujeto mostrativo funciona como las señales del camino (Wegweiser), indican, muestran sin decir, en cambio el yo modal dice, juzga, valora, esto es, vincula o separa lo indicado con el campo simbólico, o términos de Frawley, con el sistema de creencias del hablante.

Lo más interesante de la postura de Frawley es que la deixis se mantiene estructuralmente en la modalidad epistémica. El saber, los juicios y valoraciones, se definen por relación a un centro epistémico, a una fuente del conocimiento (the source of knowledge) que es el eje deíctico principal del saber (Frawley, 1992: 412). La caracterización de este punto deíctico como la fuente del conocimiento puede ser puesta en relación con la descripción de Bühler del sistema de coordenadas de la deixis como origen (origo). Es decir, el yo modal es el origen de las diferentes actitudes epistémicas que el sujeto asume.

El segundo rasgo deíctico de la modalidad es una consecuencia de lo anterior. Tomando como punto de referencia epistémico la fuente del 
saber se puede establecer una direccionalidad respecto de ella ${ }^{10}$. El tercer rasgo es la gradualidad del saber (remoteness). Confidencia, compromiso, firmeza son modos de establecer una distancia relativa entre la fuente de conocimiento y lo dicho.

Con las modalidades deónticas sucede exactamente lo mismo: son una reescritura del campo mostrativo; vinculan la deixis con la competencia volitiva del sujeto. Desde este punto de vista, la modalidad deóntica no es más que la imposición de un mundo expresado al mundo referencial de otros sujetos (Frawley, 1992: 420). El análisis de esta modalidad muestra que requiere los mismos rasgos deícticos analizados en la modalidad epistémica, pero transformados ahora por su vínculo con la voluntad. Sin entrar en detalles la diferencia sustancial que existe entre los dos tipos de modalidades es la siguiente: la modalidad epistémica privilegia la coordenada deíctica de la fuente del saber, por ello, se sitúa en el punto de vista del hablante; en cambio, la modalidad deóntica privilegia el eje deíctico contrario, a saber, la meta (goal). Se sitúa en la perspectiva de los otros a quienes impone un mundo expresado (Frawley, 1992: 425).

Este análisis de la estructura deíctica de las modalidades tiene la ventaja de: $\boldsymbol{\alpha}$ ) mantener la distinción de ambos mediante el recurso de la diferencia que existe entre mostrar y decir, $\beta$ ) al afirmar que la deixis se mantiene como estructura formal de las modalidades, la referencia a la subjetividad se transforma en un elemento esencial. Modalidad y deixis son egocéntricas, $\chi$ ) posibilitar un análisis ulterior en donde se especifique por qué determinadas modalidades (por ejemplo, la necesidad) llevan consigo una concepción de un sujeto que carece de estructura deíctica, es decir, que mira desde ningún lugar. La carencia de estructura deíctica de este tipo de subjetividad es la que posibilita los discursos objetivos.

Tomando en cuenta la distinción y relación entre deixis y modalidad, creo que se puede reorganizar las relaciones entre los roles subjetivos de la manera que sigue: la noción de locutor expresa el eje de coordenadas de la deixis, identifica el origen del enunciado por referencia a la voz. Por ello lo designo como sujeto deíctico. Ciertamente que el estatuto del locutor * es el sujeto hablante entendido ya no como el sujeto empírico de Ducrot, sino como un sujeto histórico que tiene estados intencionales y que obra aquí y ahora. Este es el sentido que Ducrot le asigna cuando habla de la firma:

En la conversación oral cotidiana, la que cumple ambas funciones de la firma es la voz. Por una parte, la voz puede servir para hacer saber quién es el locutor, es decir, a quién designan los morfemas de primera persona (...) Y por otra parte, ella autentifica la homologación del locutor con un individuo empírico particular, aquel que produce efectivamente el habla (Ducrot, 1986: 199). 
La homologación es redundante, no agrega absolutamente nada al primer acto de identificación. En efecto, al identificar al locutor por su voz y a quién dice "yo", le imputamos la responsabilidad del enunciado, es decir, lo identificamos como un sujeto histórico.

Los enunciadores y el locutor $\lambda$ se reducen a la modalidad, es decir, a las diversas actitudes intencionales (epistémicas y volitivas) que el sujeto puede asumir. Las actitudes intencionales no deben ser interpretadas como facultades psíquicas, sino como los topoi en donde se cristalizan las posiciones valorativas de las diferentes praxis históricas (AnscombreDucrot, 1988: 218). El sujeto modal puede asumir múltiples posiciones como si fuera un drama: puede proponer su propio punto de vista, puede reproducir puntos de vista ajenos, puede asimilarse o distanciarse de las perspectivas ajenas, o puede eliminarse como sujeto modal y representarse como si fuera un ser del mundo (locutor $\lambda$ ), es decir, adoptar la perspectiva y deixis objetiva. Cada una de estas posibilidades, en las que el sujeto modal se representa, da cuenta de un enunciador.

\section{NOTAS}

1. El trabajo se restringe tan sólo a esta cuestión. Deja de lado la reformulación de la teoría ducrotiana que se denomina "bloques semánticos".

2. Ducrot ilustra esta idea con los actos ilocutivos, la argumentación y las expresiones exclamativas. La idea es que, por ejemplo, un enunciado del tipo " $A$ gana apenas $X$ francos por mes" sólo tiene sentido cuando suponemos una elección del hablante: "apenas" en vez de "casi". Esta elección da cuenta a su vez de otra elección, a saber, el topos desde el cual se debe interpretar el enunciado (cuanto más gana alguien menos lástima provoca) y la intención del hablante (provocar lástima). Así entonces, el sentido de un enunciado supone la cualificación de las elecciones que constituyen su enunciación.

3. La definición textual dice así: "Un punto de vista es, por definición, un punto de vista $\mathrm{X}$ acerca de $\mathrm{A}$, un discurso $\mathrm{X}$ acerca de $\mathrm{A}$, lo que determina una relación entre $\mathrm{X}$ y $\mathrm{A}$ " (Donaire, 2004: 126).

4. El ejemplo que Donaire propone es "adorable" (selección de calificación positiva).

5. El ejemplo es "detestable" (exclusión de calificación positiva).

6. Este el motivo por que Paul Ricoeur (1995) cuando trata estos problemas dice: "Se trata, más bien, de una sola función considerada bajo el ángulo de dos cuestiones diferentes. El punto de vista responde a la pregunta: ¿Desde dónde se percibe lo que se muestra por el hecho de ser narrado? Por lo tanto, ¿̇desde dónde se habla? La voz responde a la pregunta: ¿Quién habla aqué?... sólo subsiste una diferencia entre punto de vista y voz: el punto de vista deriva de un problema de composición (como hemos visto en Ouspenski); así, sigue estando dentro del campo de investigación de la configuración narrativa; la voz, en cambio, incumbe ya a los problemas de comunicación en la medida en que está dirigida a un lector, se sitúa así en el punto de transición entre configuración y refiguración, en cuanto que la lectura marca la intersección entre el mundo del texto y el del lector. Precisamente son estas dos funciones las intercambiables" (Ricoeur, 1995: 531-532). 
7. Esta es la idea central de la polifonía de Bajtín-Voloshinov. Su crítica al objetivismo abstracto se funda en la idea de que el sistema de la lengua excluye la responsabilidad del acto libre.

8. La referencia a Bühler es mía y no de Frawley.

9. Por ello las dos categorías básicas de la modalidad, según Frawley, son las categorías de realidad (realis) e irrealidad (irrealis). La primera se da en la afirmación y consiste que la coincidencia entre el mundo expresado y el mundo de la referencia, es decir, del campo mostrativo. La irrealidad se da por la negación y radica precisamente cuando el mundo expresado y el mundo de la referencia no coinciden. Frawley denomina a la categoría realis modalidad epistémica.

10. Frawley distingue tres tipos de relaciones entre la fuente y lo dicho: a) el yo (selff) es el que se presenta a sí mismo como la fuente del conocimiento (juicios, inferencias y confidencias) b) la fuente del conocimiento no proviene del yo, sino se basa en los sentidos (evidencia directa o evidencia sensorial) c) el conocimiento proviene de otros (evidencia indirecta, citas, informes, etc.).

\section{REFERENCIAS BIBLIOGRÁFICAS}

ANSCOMBRE, J. C. \& DUCROT, O. (1988) La argumentación en la lengua. Madrid: Gredos.

BAJTIN, M. (1997) Hacia una filosofia del acto ético. De los borradores. $Y$ otros escritos. Barcelona: Anthropos.

BÜHLER, K., (1999) Sprachtheorie. Stuttgart: Lucius \&Lucius UTB.

DONAIRE, M. L. (2000) 'Polifonía y punto de vista', Revista Iberoamericana de Discurso y Sociedad, Vol 2, 4: 73-87.

DONAIRE, M. L. (2004) 'La polifonía, una relación binaria', en E. Arnorux \& M.M. García Negroni (Comps.), pp. 117-133. Homenaje a Oswald Ducrot. Buenos Aires: EUDEBA.

DUCROT, O. (1986) El decir y lo dicho. Polifonía de la enunciación. BarcelonaBuenos Aires: Paidós.

DUCROT, O. (2004) 'Sentido y argumentación', en E. Arnorux \& M. M. García Negroni (comps.), pp. 359-370. Homenaje a Oswald Ducrot. Buenos Aires: EUDEBA.

FRAWLEY, W. (1992) Linguistic Semantics. Hillsdale-New Jersey-Hove-London: Lawrence Erlbaum Associates.

GARCIA NEGRONI, M. A \& TORDESILLAS COLADO, M. (2001) La enunciación en la lengua. De la deixis a la polifonia. Madrid: Gredos.

GENETTE, G. (1989) Figuras III. Barcelona: Editorial Lumen.

GUIMARAES, E. (2004) 'Argumentación y acontecimiento', en E. Arnorux \& M.M. García Negroni (Comps.), pp.211-225. Homenaje a Oswald Ducrot. Buenos Aires: EUDEBA.

RICOEUR, P. (1995) Tiempo y Narración II. México: Siglo XXI.

NAGEL, TH. (1996) Una visión desde ninguin lugar. México: FCE.

VOLOSHINOV, V. (1992) El marxismo y la filosofia del lenguaje. Madrid: Alianza.

ADRIÁN BERTORELLO es Profesor y Licenciado en Filosoff́a (UCA), Magister en Análisis del discurso (UBA). Docente e investigador de la Universidad de Buenos 
Aires (UBA). Profesor Titular de Análisis del Discurso (UCES). Ex Becario del DAAD (Albert-Ludwigs Universität Freiburg); ex becario de CONICET (Centro de Investigaciones Filosóficas); ex Becario del Stipendienwerk Lateinamerika-Deutschland (UCA). Diversas publicaciones en el área de filosofía hermenéutica.

Correo electrónico: adrianbertorello@fibertel.com.ar 